\title{
FINALITATEA SIMBOLIC-MITICĂ A CREAȚIEI DE SENS ÎN CONFIGURAREA ONTO-TEOFANIEI POETICE BLAGIENE
}

\author{
Mihai-Andrei Lazăr \\ lazarandini@yahoo.com \\ Universitatea „Babeș-Bolyai,” Cluj-Napoca
}

\begin{abstract}
In this paper, we seek to demonstrate how Lucian Blaga's poetic universe is double layered, in the sense that one can distinguish between, on the one hand, a phenomenological plane, characterized by a pervasive sense of the inexorable passage of time and of human mortability and, on the other hand, a supramundane (noumenal) plane which, in a profane world, has become unattainable and therefore intensifies the individual's sense of loneliness and estrangement from a sacred universe. We attempt to show how there two planes interfere, mainly through revelations of the divine (epiphanies). In our paper, we follow a poetic and stylistic approach, founded on Mircea Borcilă's attempt to formulate a poetic typology aiming to highlight the intrinsec mechanisms of a poetic finality oriented towards the creation of meaning, therefore inscribing Blaga's poetry on the coordinates of a symbolic-mythical pattern. The linguist's theory draws on Blaga's conception of the duality of metaphor ("plasticizantă" and "revelatorie"), the latter having a revelatory function and being subdivided by Borcilă according to a cultural finality into a "plastic" finality in creating poetic meaning, whose universe of reference will be modelled upon the phenomenological world, and a "revelatory" finality, whose universe of reference will be modelled upon a noumenal, transmundane world.
\end{abstract}

Key-words: phenomenological plane, noumenal plane, epiphany, symbolic-mythical pattern, ' 'revelatory" finality.

\section{Considerații generale}

În încercarea de a formula o tipologie poetică și de a surprinde mecanismele intrinseci ale creației de sens cu finalitate poetică în opera lui Lucian Blaga, exegetul Mircea Borcilă valorifică opera acestuia, nu doar în dimensiunea ei, teoretică, filosofică, ci și în cea artistică și ajunge la o concluzie revelatoare, postulând înscrierea creației poetului pe coordonatele unei lirici de factură simbolic-mitică. Lingvistul reelaborează teoria blagiană a dualităţii metaforei (plasticizantă și revelatoare), în care numai aceasta din urmă îndeplinește o funcție revelatoare, subîmpărțind-o în funcție de finalitatea de ordin cultural; autorul distinge, astfel, finalitatea „plasticizantă” în creația 
de sens poetic, al cărei univers referențial, ca nucleu generativ al textului poetic, va fi construit după un model comun, al lumii fenomenale (sau concret-senzoriale). Această finalitate a creației de sens poetic se distinge, în tipologia poetică propusă de Mircea Borcilă, de finalitatea „revelatorie”, al cărei câmp se constituie urmând „un model abstract, al unor lumi «ideale» (sau «numenale»)" (Borcilă 187).

Cele două tipuri de metafore, opinează Mircea Borcilă, declanșează procese metaforice corespunzătoare, descrise pe baza unor coduri culturale preluate din conceptualizările efectuate de către I. M. Lotman. Astfel, procesul metaforic de tip plasticizant, „,va defini și ilustra [...] un cod semiotic cultural de tip sintactic, întrucât posibilitatea funcționării lui se bazează pe un model al lumii analog lumii fenomenale”,(187) în timp ce procesul metaforic revelatoriu valorifică ,un cod semiotic cultural de tip semantic, în măsura în care funcționarea acestuia presupunea un model al unor lumi multiplu semiotizate și axiologic ierarhizate" (187). Pornind de la această dihotomie, Mircea Borcilă oferă trei criterii fundamentale pentru încadrarea unei opere lirice într-o anumită tipologie a textualității poetice; criteriul „orientării” sau ,al intenției generale” a procesului de poesis descriptiv permite decelarea a două forme de finalitate poetică, lirica lui Lucian Blaga actualizând finalitatea „revelatoare”, întrucât reflectă încercarea de ,revelare” a unor „«esențe ale lumii» obscurizate de diversitatea ei fenomenală” (188) apoi, al doilea criteriu este cel al „principiului existențial-axiologic” care guvernează procesul de poesis discursiv. Opera poetului ilustrează principiul de ordin semantic, care ,se bazează [...] pe presupoziția că anumite fenomene reperabile în planul designațional al lumii date posedă o semnificație prin ele însele [...], în măsura în care le «transcende» pe un plan ontologic mai profund al «esențelor» și axiologic superior al «valorilor»" (189) În sfârșit, aplicând criteriul modelului de construcție referențială, Mircea Borcilă emite ipoteza potrivit căreia ,lirica lui Lucian Blaga ar corespunde unui model de tip simbolic, deoarece la baza acestor texte stă [...] o orientare «revelatoare» a procesului de poesis, ceea ce presupune o dedublare a procesului designațional (ontologic) și o disparitate radicală între cele două nivele ale acestui plan / nivel «fenomenal» și cel al «esențelor»” (190). Interpretând această recalibrare a dualităţii metaforice blagiene, fundamentată de Mircea Borcilă, Oana Boc valorifică aserțiunile lui Lucian Blaga: poetul ,,acordă metaforei un statut ontologic, considerând că metaforicul ține de ordinea structurală a spiritului uman, limbajul poetic fiind «în cea mai intimă esență a sa ceva metaforic»”, (Boc 230) încât „,teoria dualității metaforice blagiene este axată, așa cum remarcă M. Borcilă (Borcilă 1997), pe diferența fundamentală dintre creativitatea din cadrul limbajului (sfera metaforicii limbajului), ilustrată prin metaforele plasticizante, și creativitatea 
culturală (care integrează și sfera creațiilor literar-artistice), ilustrată prin metaforele revelatoare, realizate prin mijloace de limbaj, dar cu o funcție proprie, diferită de cea a limbajului.” (230) În continuare, ,interpretând dintr-o perspectivă funcțională această dihotomie metaforică blagiană (disociabilă mai ales pe criteriul fundamental al menținerii vs. al amânării sau suspendării «semnificației obișnuite a faptelor»), M. Borcilă distinge două principii și finalități distincte situate la niveluri semantice diferite: pe de o parte principiul lingvistic, plasticizant, care actualizează finalitatea semnificativă din teoria coșeriană și se situează la nivelul semnificatului (conținut al limbii), iar, pe de altă parte, principiul translingvistic, poetic, care vizează finalitatea poetică, și se situează la nivelul sensului (conținut specific textului, actului discursiv). "(290)

În egală măsură, Mircea Borcilă aduce, prin aceste considerente, rafinări ale analizelor desfășurate de Sextil Pușcariu și de Tudor Vianu, savanți care au încercat, de asemenea, să descrie lirica blagiană în termenii unei încadrări tipologice. Astfel, raportându-se la studiile lui Pușcariu, lingvistul opinează că „cele mai multe observații ale lui Pușcariu asupra textelor liricii blagiene tind să vină în întâmpinarea unei asemenea abordări poetice funcțional-tipologice. El definește aceste texte ca reprezentând o poezie de tip «filosofic» sau «metafizic», în sensul unei orientări primordiale spre «conținut» (nu spre «expresia lingvistică») și, mai precis, în sensul că această poezie se «construiește» printr-o anumită «atitudine spirituală» sau «viziune asupra lumii»» (Borcilă 135), opinie argumentată și prin sugestia că „la fel de pregnante sunt, uneori, observațiile lui Pușcariu în ce privește modul specific de «dezvoltare semantică» a termenilor selectați în opera blagiană” (137)' ceea ce conduce la o ,înțelegere profundă a funcționalității mitice a textelor discutate"(139). Pe de altă parte, din cercetările lui Tudor Vianu, Mircea Borcilă reține faptul că „tipul poetic blagian apare circumscris, în accepția cea mai largă, tot prin integrarea textelor sale, în «poezia metafizică», «de cunoaștere», sau, mai restrictiv, în «lirica gnoseologică». Aportul nou și valoros al încadrării propuse de Vianu provine, însă, fără îndoială, din situarea lui Blaga, alături de Ion Barbu, și din disocierea lor netă în raport cu lirica (antumă) a lui Eminescu și cea a lui Arghezi. Reperarea primă a tipului «metafizic» se face, evident, pe aceeași bază a orientării spre «substanță» (=conținut), și nu spre «formă» (=expresie), comună atât lui Blaga, cât și lui Barbu. Vianu oferă, însă, și o formulă definitorie, pentru acest tip poetic, reținând orientarea funcțională a textelor celor doi poeți spre «sensibilizarea unui înțeles metafizic».”( 139)

Pornind de la aceste clarificări terminologice, ne propunem să demonstrăm validitatea și aplicabilitatea încadrării tipologice pe care o elaborează Mircea Borcilă, ilustrând-o cu exemple selectate din creația poetului, nu înainte de a circumscrie o perspectivă de ansamblu asupra 
climatului cultural și a modelelor epistemologice, postulate în perioada în care Lucian Blaga își desfăşura activitatea artistică, climat remarcabil reconstituit de către exegetul clujean Liviu Petrescu, în lucrarea Poetica postmodernismului. De asemenea, pe parcursul exemplificărilor noastre, nu vom putea neglija o serie de considerații filosofice pe care Lucian Blaga le expune pe larg în studiul Cenzura transcendentală, parte integrantă a Trilogiei cunoașterii. În fond, deși recunoaștem ireductibilitatea polivalenței poeticii blagiene la pistele trasate în filosofie, nu putem să negăm faptul că unele dintre aserțiunile privitoare la raportul omului cu transcendentul și la poziția sa față de cunoaștere se dovedesc un instrument util în direcția schițării unor trasee hermeneutice neexplorate până acum, în direcția maximalizării potențialităților semnificaționale ale textelor lirice.

Așa cum foarte convingător o demonstrează Liviu Petrescu, întreaga operă blagiană poate fi plasată sub cupola celui de-al doilea modernism, după ce primul începuse să traverseze o perioadă de criză, treptata sa subminare fiind determinată, cu precădere, de o atitudine de mefiență față de supremația absolută a unui model epistemologic de tip știinţific, supus unui ineluctabil proces de dinamitare, de unde și căutarea obstinată a unei paradigme epistemice alternative, ca opțiune compensatorie, urmărind să depășească modelul mecanicist. În acest sens, Lucian Blaga elaborează o, ,teorie a «crizei obiectului», teorie ce prezintă obiectul natural doar ca pe un concept sintetic, ale cărui componente nu ar avea în totalitatea lor un caracter manifest «fanic», mare parte din el rămânând ca o față ascunsă, «criptică»», a obiectului, ca un «mister deschis»»"( Petrescu 53). „Ceea ce mai înainte fusese obiect neted, nedespicat - se preface în obiect despicat în două: în arătat și în ascuns.” (Blaga 164) În interpretarea exegetului Corin Braga, ,ieșind din direcția epistemologică pozitivistă a lui Auguste Comte, Blaga nu își propune să lumineze sau să reducă necunoscutul, ci încearcă să-1 fixeze într-o categorie de sine stătătoare.”(Braga 104) De aici derivă și binaritatea tipurilor de cunoaștere conceptualizate: „Primul tip - pe care, așa cum subliniază gânditorul, filosofia științei îl atribuie îndeobște discursului științific - este menit să construiască o explicaţie de tip cauzal, pentru acele structuri ale realităţii ce se situează la nivelul ei de organizare cel mai simplu"( Petrescu 53), nivel circumscris de orizontul lumii imediate, fenomenale, experiențiale. Cel de-al doilea tip de cunoaștere ar încerca ,să dea seama de alte nivele, de o complexitate sporită, ale realității, nivele identificate drept «un orizont al misterelor». Or, la un asemenea nivel de complexitate, realitatea este presupusă a prezenta anumite trăsături de «iraționalitate»" (54). De aici rezultă și o dimensiune a translogicului, a unei categorii ce nu se mai supune logicii aristotelice, ci e paradoxală, permițând, în consecință, o transfigurare a antinomiilor. 
În termenii filosofului, modelul ontologic este numit „ecstatic”, descris prin contrast cu modelul „enstatic”: „Cât timp intelectul se așază în cadrul funcțiilor sale logice normale, e enstatic. Din moment ce intelectul, pentru a formula ceva cu ajutorul conceptelor ce-i stau la dispoziție, trebuie să evadeze din sine, să se așeze cu hotărâre în afară de sine, în nepotrivire ireconciliabilă cu funcțiile sale logice, el devine ecstatic" (Blaga 94). Pe această cale, conchide exegetul, modelul științific este gradual înlocuit de unul artistic: ,în ordine metodologică, pozițiile cele mai avansate nu mai sunt deținute, în această perioadă, de cunoașterea științifică, pe primul plan trecând cunoașterea de tip artistic (ce prezintă însă numeroase trăsături comune cu gândirea mitică)" (94).

După cum vom încerca să argumentăm în lucrarea noastră, unei asemenea dislocări de paradigmă îi va corespunde, în câmpul universului poetic, un model al lumii biplan, în care transcendentul va fi revelat prin epifanii, dar va rămâne de necuprins, condiție ce implică o stratificare a nivelurilor ontice: mundanitatea lumii fenomenale va interfera cu numenalitatea orizontului transcendental spre care accesul ființei va fi barat, iluzoriu, de unde drama condiției umane, constantă a lumii blagiene. Înainte de a trece la comentarea propriu-zisă a unor poezii ce reflectă tensiunea dată de conștiința irecuperabilității plenare a sacrului, propunem o incursiune în spațiul filosofiei blagiene, concentrându-ne asupra aserțiunilor sale privitoare la Marele Anonim și rezumând principalele direcții configurative, adoptate ca premise generale ale demersului filosofic, sugestive pentru poziția omului în sistemul ontologic guvernat de un centru noetic. Pe aceeași linie a constatării limitelor paradigmei scientiste, Lucian Blaga asociază orizontul misterului unei (auto)interogări profunde a fondului uman: „O idee științifică [...] e neasemănat mai neutrală în ce privește atitudinea spirituală a omului față de existență în genere şi față de propria existență în special.” (Blaga 11) Totodată, pentru a sugera nivelurile ontologice, precum și ierarhizarea lor întro perspectivă axiologică, dată fiind coordonata trans-fizicului, a modelului ontic abstract, filosoful face următoarea asumpție: „O concepție metafizică se caracterizează prin verticalitate, o dimensiune care la ideile științifice se apropie de limita zero.’(12) De aici și posibilitatea cartografierii dihotomice a universului poetic blagian, în raport cu lirica argheziană, circumscrisă unui orizont monoplan, pe orizontală, în absenţa dimensiunii sacrului, nedublat ontologic de un plan superior, mai profund. $\mathrm{O}$ astfel de perspectivă, opinează în continuare Lucian Blaga, obligă la o reconsiderare a statutului ființial al omului, producând mari prefaceri interioare, alimentate de nevoia aflării răspunsului la neliniștitoare întrebări existențiale, de natură a-i chestiona însuși traiectul destinal: „Verticalitatea unui gând se măsoară subiectiv după intensitatea și amplitudinea transformărilor sufletești pe care le poate produce în insul uman. Un gând vertical, înalt sau adânc, 
poate să deplaseze chiar centrul existențial al omului. Printr-un gând «vertical», care totdeauna dă un anume sens existenței, omul se poate simți dintr-odată smuls din rostul său de până aici și transportat în alt rost, în altă perspectivă, în altă universală noimă” (14). Astfel, se produc revelaţii la nivelul conștiinței, care devine problematizantă, „ideile verticale” fiind ,ideile care prin rezonanțele lor, chiar neintenționate, pot să dea un sens inedit vieții, fie de transfigurare a ei, fie de accentuare a ei, fie de negare a ei." (15) Corelând poziția epistemologică a lui Lucian Blaga cu unul dintre nucleele ideatice ale filosofiei sale, privitoare la postularea destinului creator al omului, „întru mister și pentru revelare”, în opoziţie cu existența ,pentru imediat și întru securitate”, precum și cu axul viziunii sale lirice, i.e., interpelarea divinului (ca sondare a transcendentului), deducem faptul că poetul pare din nou să expliciteze ruptura de un model epistemic scientist, prin afirmații tranșante, conchizând că „Știința a luat naștere printr-un act de renunțare ce s-a dezvoltat sub semnul stăpânitor al acestui act. Prin actul de renunțare la contactul intim și permanent cu puterile demiurgice ale omului, ea n-a putut să se substituie metafizicii tocmai din acest motiv.” (16)

\section{Organizarea ontologic-biplană a universului liric blagian}

După acest excurs teoretic, propunem să ne îndreptăm atenția asupra principalelor coordonate ale universului poetic configurat de Lucian Blaga, dimensiuni ce atestă dubla stratificare ontologică a cosmosului. Ca o constantă a universului liric, semnalăm năzuința restabilirii unui contact pierdut cu divinul, pe fondul conștientizării precarității ontologice și a iminenței morbului thanatic, obsesie augmentată de optica retrospectivă, care, prin anamnesis, nutrește nostalgia vârstei edenice a mitului, când nu se produsese ruptura contingentului de noetic, într-o lume ce funcționa după legea unei cronotopii sustrase determinismului spațio-temporal, ca situare a ființei în proximitatea divinului. Odată pierdută această stare privilegiată, individul este smuls din matricea sa ontologică, el devine supus legilor unei cronotopii profane, de unde tensiunea dată de perpetuarea unor polarități organizate sistemic, vertebrate de dihotomia timp arhaic - timp istoric (i. e., condiție astrală - condiție terestră). De remarcat faptul că, deși ocultat în universul sensibil, divinul îl scurtcircuitează hierofanic, încât eludarea sa nu este niciodată definitivă. Mai degrabă, o privire vizionară intuiește, prin sondarea diversității fenomenale, urmele cronotopiei mitice, până atunci camuflate, producătoare de revelații, care certifică regulatele irumperi ale unui noetism latent. Vom ilustra afirmațiile noastre prin comentarea unor nuclee semantice care susțin edificiul poetic organizat biplan. 
Astfel, menționăm, ca o primă constantă, trimiterile repetate la un imaginar originar, al Genezei, configurând primordialitatea creației divine, ca primum movens al unui univers numenal, prelapsar, proiectat mnemotic și traversat de motivul luminii. Ruptura ontologică este reflectată la nivel lingvistic prin deicticul adverbial cu semantism temporal „de-atunci” și prin selectarea formei de perfect compus a verbului ,a pieri”, ambele sugerând o vârstă a umanității edenice depășite (revolute). Pe de altă parte, contemplarea iubitei aduce o revelație de tip hierofanic, dată fiind intuirea unui fond originar: „Lumina ce-o simt / năvălindu-mi în piept când te văd, / oare nu e un strop din lumina / creată în ziua dintâi, / din lumina aceea-nsetată adânc de viaţăa [...] // Dar undea pierit orbitoarea / lumină de-atunci - cine știe? // Lumina, ce-o simt năvălindu-mi / în piept când te văd - minunato, / e poate că ultimul strop / din lumina creată în ziua dintâi. " (Lumina) (Blaga 45) Într-un alt poem (A fost cândva pământul străveziu), este explicitată instalarea unei temporalităţi postlapsare, disjunctă în raport cu anistorismul originar, simultan cu o mișcare de recuperare cronotopică, hierofanică: „A fost cândva pământul nostru străveziu / ca apele de munten toate ale sale, / în sine îngânând izvodul clar și viu. / S-a-ntunecat apoi, lăuntric, ca de-o jale, / de bezne tari ce-n niciun grad nu se descriu. / Aceasta-a fost când o sălbatică risipă / de frumuseți prilej dădu întâia oară / păcatului să-și facă pe subt arbori cale?// Nu pot să știu ce-a fost prin vremi, odinioară, / știu doar ce văd: subt pasul tău, pe unde treci / sau stai, pământul înc-o dată, pentr-o clipă, / cu morții săi, zâmbind, se face străveziu. / Ca-n ape fără prunduri, fabuloase, reci, / arzând se văd minuni - prin lutul purpuriu.” (Blaga 86) În aceeași ordine de idei, un poem precum Inaintarea lor și intoarcerea noastră circumscrie dezideratul recâștigării apartenenței la o umanitate adamică, prin resemantizarea imaginarului biblic: „Pe acelaș[i] drum uneori noi nentoarcem / până-n mijlocul caldei, aievei / lumini, care-n ea ține șerpii / și basmele Evei." (99) În esenţă, nostalgia primordialităţii vertebrează întreaga viziune lirică: „În apropiere e muntele meu, munte iubit. / Înconjurat de lucruri bătrâne / acoperite cu mușchi din zilele facerii" (Liniște între lucruri bătrâne) (144)

O altă constantă recurentă în lirica blagiană, confirmând organizarea biplană a universului de discurs liric, este dată de accentuarea crizei incomunicabilităţii omului modern, manifestată prin blocarea oricărui canal de comunicare cu transcendentul, polarizând tensiunea dintre lumea suprafenomenală și cea sublunară. În acest sens, exegetul George Gană intuiește „o afirmare patetică a individului, prin accentuarea extremă a subiectivității sale în raportul eu-lume, prin exacerbarea sensibilității la metafizic și prin aspirația la comunicarea profundă cu universul, privilegiindu-se sentimentul cosmic." (Gană 105), ceea ce corespunde, în opinia criticului literar 
Ion Pop, unei viziuni mitice, care ,se caracterizează prin ruptura ontologică, marcată de depăşirea timpului paradisiac și de sentiemntul alienării omului de natura originară. Se impun ipostaza meditativă a eului, excesul de problematizare, suferința provoactă de pierderea contactului nemediat cu universul, timp al «tristeții metafizice» și al nostalgiei nevindecate a spațiului edenic, alături de voința de integrare a subiectului fragmentar în Totul congener.” (Pop 33) ${ }^{31}$ Ipostaza predilectă a divinului va fi, așadar, cea de deus otiosus, ca prevalență a unui sentiment de nonparticipare și de non-aderare la universul sensibil: „O durere-ntotdeauna mi-a fost singurătatea ta ascunsă / Dumnezeule, dar ce era să fac?[...] // Ești muta, neclintita identitate / (rotunjit în sine a este a), / nu ceri nimic. / Nici măcar rugăciuna mea.” (Psalm) (134-135) „Mistuiți de răni lăuntrice ne trecem prin veac. / Din când în când ne ridicăm ochii spre zăvoaiele râului, / apoi ne aplecăm capetele în și mai mare tristețe. / Pentru noi cerul e zăvorât, și zăvorâte sunt și cetățile.” (Noi cântăreții leproși) (166) ${ }^{33}$; „Unde ești, Elohim?/ Lumea din mânile tale-a zburat / ca porumbelul lui Noe. / Tu poate şi astăzi o mai aştepţi. / Unde eşti, Elohim?/ Umblăm turburaţi şi fără de voie, / printre stihiile nopţii te iscodim, / sărutăm în pulbere steaua de subt călcâie / şi-ntrebăm de tine / - Elohim! / Vântul fără de somn îl oprim / şi te-ncercăm cu nările, / Elohim! / Animale străine prin spaţii oprim / şi le-ntrebăm de tine, Elohim! / Până în cele din urmă margini privim, / noi sfinţii, noi apele, / noi tâlharii, noi pietrele, / drumul întoarcerii nu-l mai ştim, / Elohim, Elohim!” (Ioan se sfâşie în pustie) (228), statuarea fenomenalului și a numenalului ca necomunicabile fiind accentuată și în alte poeme, în care vârsta adamică supraviețuiește doar în și prin amintire: „Unde eşti astăzi nu ştiu. / Vulturii treceau prin / Dumnezeu deasupra noastră. / Alunec în amintire, e-aşa de mult de-atunci./ Pe culmile vechi unde soarele iese din pământ / privirile tale erau albastre şinalte de tot. / Zvon legendar se ridica din brazi. / Ochi atotînţelegător era iezerul sfânt.” (Amintire) (158) .

O altă sursă de tensiune semantică, imagistică și ideatică este dată de interferențele dintre cele două regimuri ontologice, interferențe care nu fac decât să adâncească funciara criză a cunoașterii metafizice, reiterând plasarea omului sub zodia unei temporalităţi inexorabile. Se disting două constante ale imaginarului, pe care le vom detalia în continuare: prima este tentativa de resuscitare a sacralității arhaice, prin intuiția epifanică a unor forme de manifestare a numenalului în limitele fenomenalului, ceea ce nu are însă puterea de a smulge ființa din regimul accidentalului și al cauzalității: „Strălucitoare-n poarta raiului / sta Eva. / Privea cum ranele amurgului se vindecau pe boltă // și visătoare / mușca din mărul, / ce i 1-a-ntins ispita șarpelui. / Fără de veste / un sâmbure i-ajunse între dinți din fructul blestemat, / Pe gânduri dusă Eva îl suflă 
în vânt, / iar sâmburele se pierdu-n țărână, unde încolți. / Un măr crescu acolo - și alții îl urmară / prin lungul șir de veacuri. / Și trunchiul aspru și vânjos al unuia din ei / a fost acela, // din care fariseii meșteri / ciopliră crucea lui Isus. / Oh, sâmburele negru aruncat în vânt / de dinții albi ai Evei.” (Legendă) (60); „Cocoși apocaliptici tot strigă, / tot strigă din sate românești. / [...] / Pe mal - cu tămâie în păr / Isus sângerează lăuntric / din cele șapte cuvinte / de pe cruce.” (Peisaj transcendental) (206); „sus în lumină ce fragil / apare muntele! / Cetatea zeilor din ochii de copil / uşor se sfarmă ca mătasea veche. / Materia ce sfântă e, / dar numai sunet în ureche." (Răsărit magic) (354); „Murind zeii își lasă / în urma lor templele, / precum melcii / căsuliile goale. // Pentru mii de ani, pentru vremi fără capăt / ei și le lasă, / spre mângâierea / vârstei de azi și de-apoi. / Dar niciun vestigiu al erei de aur, / oricare ar fi chipul lui, / nu-nvinge tristețea noastră / în fața timpului.” (Murind zeii îşi lasă) (Blaga 97); „Clădită din nisip, din piatră de răsip, / această catedrală dăinuie în vânt. / N-o clatină nimic, nici zbucium din pământ; / nici focuri din înalt. Privind-o-n noapte / prin constelații parcă însumi mă-nfirip. // Prin veac cândva s-a dezbrăcat de schele / făptura de nisip, biserica ce e, / o taină-a-ei prin vremi să tâlcuiască. // Temei aflând în câmpuri dintre stele, / ea n-are unde să se prăbușească. / Celest în sine cumpănită, biruie / în timpulvânt, și-acolo sus, mai sus de vânt.” (Catedrală printre stele) (113-114); „Nu-1 mișcă știutele / crânguri cu ciutele. / Cărarea cu umbrele, / iezerul, umbrele / nu-1 cheamă. Copitele / sfarmă ispitele. // Prin ceață când lunecă / zări el adulmecă, / nu apropiatele, / ci depărtatele. // Ciulindu-și urechile / prinde străvechile / rotiri, sus, de tulbure / foc și de murmure. // Și-aude, subt naltele, / unele, altele / erele, sferele." (Cerbul cu stea în frunte) (116 ); o altă obsesie a acestui tip de imaginar vizionar, decelabilă prin recurentele epifanii, este cea a panalfabetismului cosmic, a diversităţii fenomenale care se cere tălmăcită în sensul decriptării unui sistem hieroglific ce traduce divinul: „În chip de rune, de veacuri uitate, / poartă-o semnătură făpturile toate. / Slăvitele păsări subt aripi o poartă / în liturgice zboruri prelungi ca viaţa. / În slujba luminii, urmă fără de toartă, / luna și-o ține ascunsă pe fața / vrăjită să nu se întoarcă. // Stane de piatră, jivine, cucută / poartă-o semnătură cu cheie pierdută. / Pecete tăinuită de două ori - / fată de foc, arătare, care pe țărm / ridici acum brațele peste mare, / o porți subsuori. // Rune, pretutindeni rune, / cine vănseamnă, cine vă pune? / Făpturile toate, știute și neștiute, / poartă-o semnătură - cine s-o-nfrunte? / crinii muntelui - subtlunari - / și-o duc neajunsă pe creștet. / Subt ceruri muntele-o poartă pe frunte.” (Rune) (Blaga 262); „Sus cocorii desfășoară / Ieroglife din Egipt. / Dacă tâlcul l-am pricepe / Inima ar da un țipăt.” (Înviere) (66); „În satul meu, în Câmpia Frumoasei / în preajma turnului, pietrele stau / pe subt plopi. E primăvară și pietrele - stau. / Unele poartă încă inscripții chirile. / 
Este totdeauna ceva ce-n urmă rămâne, / Sunt ale părinților, pietrele - / și ale părinţilor lor.” (Judecată în Câmpul Frumoasei) (76).

O a doua constantă a imaginarului, ce atestă interferența celor două regimuri ontologice, este desacralizarea transmundanului printr-o mutație de regim al ființării. Concret, îngerul, reprezentat, în creștinism, ca făptură eterală, veșnică, aparținând orizontului transcendental, ca mediator între uman și divin, traversează un proces de profanizare, constatându-se rupturi de nivel ierarhic, pierderea condiției divine prin regresia la condiția umană, supusă degradării (dată fiind plasarea în regimul contingent); de aici, împărtășirea din substanța sublunară. Mutația de regim ontologic este explicitată prin plasticitatea imaginilor, contaminarea de densitate materială fiind simptomatică în acest sens, întrucât reflectă descompunerea, înaintarea ineluctabilă spre moarte, dinamitându-se, astfel, ca trăsătură distinctivă a făpturilor celeste, atributul „imortalitate / înveșnicire” (ca înscriere în circuitul devenirii temporale): „Pretutindeni pe pajiști și pe ogor / serafimi cu părul nins / însetează după adevăr, / dar apele din fântâni / refuză gălețile lor. / Arând fără îndemn / cu pluguri de lemn, / arhanghelii se plâng / de greutatea aripelor, / trece printre sori vecini / porumbelul sfântului duh, / cu pliscul stinge cele din urmă lumini, / Noaptea îngerii goi / zgribulind se culcă în fân: / vai mie, vai ție, / păianjeni mulți au umplut apa vie, / odată vor putrezi și îngerii sub glie, / țărâna va avea poveștile / din trupul trist.” (Paradis în destrămare) $(194)^{45}$; „Arhanghelii sosiți să pedepsească orașul / s-au rătăcit prin baruri cu petele arse. / Danțatoarea albă le trece prin sânge, râzând s-a oprit / pe-un vârf de picior ca pe-o sticlă întoarsă." (Veac) (226)

\section{Concluzii}

În urma celor enunțate, considerăm că structurarea biplană a universului liric configurat de Lucian Blaga se integrează tipologiei textualităţii poetice simbolic-mitice, descrisă de Mircea Borcilă. Organizarea pe verticală, prin coexistența planului fenomenal cu cel transcendental, certifică, prin imaginarul mitico-religios, parcurgerea unei queste a inițierii sacrale, declanșată de instaurarea unei crize a cunoașterii metafizice, alimentată de o conștientizare a precarității ontologice și articulată de o năzuință a recuperării unei cronotopii arhaice, edenice. Motivele mitico-religioase sunt, însă, resemantizate, în acord cu crezul poetic al autorului: „în poezia mea sunt frecvente și motivele mitice, chiar teologice. Dar de aceste elemente uzez în chipul cel mai liber, ca mijloace de expresie poetică. Motivele nu sunt tratate «dogmatic». Le folosesc în sens 
totdeauna creator, liber, le modific și le amplific după necesități. Născocesc motive mitice la fiecare pas, fiindcă fără de-o gândire mitică nu ia ființă, din păcate sau din fericire, nicio poezie.” (Blaga 171) și nu s-ar fi născut, am adăuga noi, nici onto-teofania poetică, înscriind ființa pe orbita existenței ,întru mister și pentru revelare”.

\section{Bibliografie:}

Blaga, Lucian. Cenzura transcendentă. București: Humanitas, 1993.

Blaga, Lucian. Luntrea lui Caron. București: Humanitas, 2006.

Blaga, Lucian. Opere, Vol. 1. Poezii. București: Minerva, 1974.

Blaga, Lucian. Poezii. Antologie, prefață, tabel cronologic, referințe critice și bibliografice de Paul Dugneanu, Galați: Porto-Franco, 1992.

Blaga, Lucian. Opera poetică. Prefață de George Gană, Ediţie îngrijită de George Gană și Dorli Blaga, București: Humanitas, 2012.

Blaga, Lucian. Trilogia cunoaşterii: Eonul dogmatic. Cunoașterea luciferică. Cenzura transcendentală. București: Fundația Regală pentru Literatură și Artă, 1943.

Boc, Oana. Metafora și instituirea sensului poetic. O privire dinspre și înspre Blaga, în Qvaestiones Romanicae. Lucrările Colocviului Internațional Comunicare și Cultură în Romania Europeană. Interferențe și contraste în România, VIII/1, Szeged Jatepress, 2020, p. 226-235.

Borcilă, Mircea. Contribuții la definirea tipului poetic al textelor lui Blaga, în Cercetări de lingvistică, anul XXXVII, nr. 2 (iulie - decembrie), , București:Editura Academiei Române, 1992, p. 133-141.

Borcilă, Mircea. „Contribuții la elaborarea unei tipologii a textelor poetice”, în „SCL” (XXXVIII), nr. 3, 1987, p. 185-196.

Braga, Corin. Lucian Blaga. Geneza lumilor imaginare, București:Tractus Arte, 2013.

Gană, George. Opera literară a lui Lucian Blaga. Editura Minerva, 1976.

Petrescu, Liviu. Poetica postmodernismului. Pitești: Editura Paralela 45, 2011.

Pop, Ion. Lucian Blaga. Universul liric. București: Editura Cartea Românească, 1981. 